\title{
Correction to: Synthesis, characterization and ampyrone drug release behavior of magnetite nanoparticle/2,3- dialdehyde cellulose-6-phosphate composite
}

\author{
Sherif M. A. S. Keshk (D) Adel A. El-Zahhar • Qana A. Alsulami • \\ Abdullah G. Al-Sehemi - Mariusz Jaremko - Samir Bondock - Thomas Heinze
}

Published online: 18 December 2019

(C) Springer Nature B.V. 2019

\section{Correction to: Cellulose \\ https://doi.org/10.1007/s10570-019-02887-y}

In the original publication of the article, one of the coauthors name was mistakenly missed out. It has been updated in this correction.
Publisher's Note Springer Nature remains neutral with regard to jurisdictional claims in published maps and institutional affiliations.
The original article can be found online at https:// doi.org/10.1007/s10570-019-02887-y.

S. M. A. S. Keshk ( $\square)$

Nanomaterials and Systems for Renewable Energy Laboratory, Research and Technology Center of Energy, Technoparc borje cedria, BP 095, Hammam Lif, Tunisia e-mail: keshksherif@gmail.com

\section{A. A. El-Zahhar · A. G. Al-Sehemi · S. Bondock} Department of Chemistry, College of Science, King Khalid University, P.O. Box 9004, Abha 61413, Saudi Arabia

A. A. El-Zahhar

Hot Labs., Nuclear Chemistry Department, Center Atomic Energy Authority, Cairo 13759, Egypt

Q. A. Alsulami

Chemistry Department, Faculty of Science, King

Abdulaziz University, P.O. Box 42805, Jeddah 21589 ,

Saudi Arabia

\author{
M. Jaremko \\ Biological and Environmental Science and Engineering \\ (BESE), King Abdullah University of Science and \\ Technology (KAUST), Thuwal 23955-6900, Saudi Arabia \\ S. Bondock \\ Chemistry Department, Faculty of Science, Mansoura \\ University, Mansoura, Egypt \\ T. Heinze \\ Center of Excellence for Polysaccharide Research, \\ Institute of Organic Chemistry and Macromolecular \\ Chemistry, Friedrich Schiller University Jena, \\ Humboldtstr. 10, 07743 Jena, Germany
}

